Article

\title{
Preparation of Yttria-Stabilized Zirconia Hollow Sphere with Reduced Shell Thickness by Controlling Ambient Temperature during Plasma Process
}

\author{
Lina Zhao ${ }^{1,2}$, Zhi Zhang ${ }^{2}$, Yugang Duan ${ }^{1, *}$, Hong Cui ${ }^{2}$ and Yong Gao ${ }^{2}$ \\ 1 State Key Lab for Manufacturing Systems Engineering, School of Mechanical Engineering, \\ Xi'an Jiaotong University, Xi'an 710049, China; zhaoln@stu.xjtu.edu.cn \\ 2 Xi'an Aerospace Composite Research Institute, China Aerospace Science and Technology Corporation, \\ Xi'an 710025, China; zzhorse@126.com (Z.Z.); cuih1969@126.com (H.C.); g15229292125@163.com (Y.G.) \\ * Correspondence: ygduan@mail.xjtu.edu.cn; Tel.: +86-136-0918-7679
}

Received: 30 May 2018; Accepted: 8 July 2018; Published: 11 July 2018

\begin{abstract}
Yttria-stabilized zirconia (YSZ) hollow sphere (HS) powder is a novel potential feedstock material for the plasma spraying of next generation advanced thermal barrier coatings with low thermal conductivity and high sintering resistibility. In this study, YSZ HS powders were prepared by plasma treatment with/without a heat preservation zone around the flying path of the particles during plasma flame. The results of the scanning electron microscopy of YSZ HS powders showed that HS prepared with a heat preservation zone during the plasma process exhibited a regular spherical morphology and a homogeneous thin shell structure. Due to the sufficient heating of the shell regions, the HS powder presented a well densified shell structure. Furthermore, the mechanism of formation of the HS powder with reduced shell thickness was also discussed based on the analysis of the evolution of the powder structure. This kind of hollow sphere powder with a very thin shell structure provides a new alternative feedstock material for the development of next generation high performance thermal barrier coatings.
\end{abstract}

Keywords: yttria-stabilized zirconia; hollow sphere; shell thickness; plasma process

\section{Introduction}

Thermal barrier coatings (TBCs) are refractory oxide ceramic coatings that are extensively used for protecting and improving the durability of hot section parts in aircraft engines, industry gas turbines, and rocket engines [1-8]. Yttria-stabilized zirconia (YSZ) exhibits low intrinsic thermal conductivity, a relatively high thermal expansion of coefficient, good erosion resistance, high strength, and high melting point, which makes it a suitable ceramic material for the top coating of TBCs $[9,10]$. YSZ TBCs are extremely beneficial as they can either increase the lifetime of hot section parts by lowering its working temperature or improve the efficiency and performance of engines by improving the engine operating temperature [11-14]. It is widely thought that both the phase transformation of the metastable $\mathrm{T}^{\prime}$ phase and the sintering-induced stiffening of the top coating would contribute to the failure of a typical YSZ top coating. However, the phase transformation from $\mathrm{T}^{\prime}$ phase to the $\mathrm{M}+\mathrm{C}$ phases needs a long and even incubation period at a very high temperature [15-17]. In addition, the sintering induced stiffening should be significant to a sufficient level before spalling failure, and this would allow a very long service lifetime, even at high temperatures [18-27]. Furthermore, by combining YSZ and other low-K ceramics into bi-layer TBCs, the lifetime can be further prolonged [28-31]. Thus, they delay the onset of the thermally induced failure mechanisms that effectively govern component durability and life. 
In general, the top coating is fabricated by atmospheric plasma spraying (APS) supplemented by electron beam physical vapor deposition (EB-PVD) and plasma spray physical vapor deposition (PS-PVD) [32-38]. During the plasma spray, powder with a diameter of around $50 \mu \mathrm{m}$ is injected into the plasma flame. The powder is melted rapidly and at the same time becomes accelerated in the plasma flame. These molten droplets with high velocities impact and spread on the surface of the substrate, then form splats after solidification. The top coating consists of overlapped splats and defects such as pores and cracks. According to the morphology, the pores in the APS TBCs can be divided into three groups: globular pores, inter-splat pores, and intra-splat pores. Among the three types of pores, the inter-splat and intra-splat pore structures play an important role in determining the thermal and mechanical properties of the top coating. Considering the significant dependence of pore healing behavior on the pore structure [39-42], the lamellar structure of the top coating is a key factor in creating high performance and long lifetime TBCs [43-47]. As all three types of pores are formed during the splat solidification and cooling process, the microstructure and the properties of the top coating significantly depend on both the spraying parameters and characteristics of the feedstock powder used [48-58]. Therefore, new feedstock powders with a large surface area are highly expected for the next generation advanced TBCs.

The following three morphologies of YSZ powder are commonly used for APS YSZ top coatings according to its manufacturing design: fused and crushed (FC) powder with an angular appearance and dense inner structure; agglomerated and sintered (AS) powder with a spherical appearance, coarse surface and porous inner structure; and plasma processed hollow sphere (HS) powder with a spherical appearance, smooth surface, and shell structure with a large pore in the center [59]. Compared to FC and AS powders, HS powder exhibits several advantages [60,61]: it can be melted more sufficiently in plasma flame due to its high surface area/mass ratio; moreover, YSZ top coatings prepared using HS powder display a distinct microstructure, such as a larger fraction of splat interface and smaller splat thickness, which lead to the lower thermal conductivity and higher sinter resistibility of the TBCs. The distinctive microstructure and enhanced properties of the TBCs prepared using HS powder are attributed to peculiar fluid dynamics, indicating that the hollow melted droplet produced from HS results in a counter-jet during the impact process [62]. Moreover, in the present-day industry of structural and protective materials, powders made up by HS have gained increasing acceptance and are used extensively in the fabrication of plasma sprayed TBCs. Thus, the synthesis of HS with the desired morphology, chemical composition, shell thickness, and mechanical properties has become an urgent matter.

The atmospheric plasma process of porous YSZ agglomerated powder is an effective method of producing HS powder given the high temperature and large thermal gradient of the plasma flame. Solonenko et al. [63] reported that when a porous particle is injected into the plasma flame, first the surface of the particle melts, then a liquid film forms rapidly on the surface; at the same time, gas in the particle is entrapped due to the surface tension of liquid film. Complete melting of the particle leads to the formation of a liquid droplet with gas entrapped in it. The entrapped gas moves to the center of the liquid droplet and the liquid droplet becomes spherical under the surface tension. When the liquid droplet leaves the plasma flame, it solidifies and forms HS with a single pore in the center.

For HS powder, at a given particle mass, reduced shell thickness leads to higher surface/mass ratio and easy melting by plasma flame, which is essential for coatings prepared under low plasma spray power such as plasma jet for inner hole due to the low thermal conductivity of YSZ. According to Solonenko et al. [64], the relative shell thickness (ratio of shell thickness and particle diameter) of HS powder produced by the plasma process is determined by the amount of gas entrapped and the temperature of the entrapped gas. HS powder with reduced shell thickness can be obtained using agglomerated powder with a larger initial porosity under the high temperature of the entrapped gas. Gulyaev [65] modified the shell thickness of HS powder through re-melting it under a controlled ambient pressure during the plasma process. Thus, the above-mentioned results indicate that 
HS powder with a reduced shell thickness can be obtained under ambient pressure lower than atmospheric pressure.

In this study, we demonstrated a method of preparing HS powder with a reduced shell thickness by controlling only the ambient temperature around the flying path of the powder when it leaves the plasma flame during the plasma process. The structures of the HS powders prepared with and without controlled ambient temperature were compared and the mechanism of the formation of HS powder with a reduced shell thickness was also comprehensively discussed.

\section{Materials and Methods}

YSZ agglomerated powder prepared by spray dry technology was processed by the atmospheric plasma process (9MC, Oerlikon Metco Inc., Churerstrasse, Pfäffikon, Switzerland) to obtain HS powder. Nitrogen $\left(\mathrm{N}_{2}\right)$ and hydrogen $\left(\mathrm{H}_{2}\right)$ were used as the primary and secondary working gases, respectively. The process parameters are listed in Table 1.

Table 1. Process parameters of 9M plasma jet.

\begin{tabular}{ccccc}
\hline Primary Gas Flow Rate $\mathbf{N}_{\mathbf{2}}$ (L/min) & Secondary Gas Flow Rate $\mathbf{H}_{\mathbf{2}}$ (L/min) & Current (A) & Voltage (V) \\
\hline 39 & 10 & 500 & 75 \\
\hline
\end{tabular}

A schematic representation of the plasma process is presented in Figure 1. YSZ agglomerated powder is vertically injected into a plasma torch at the front of the nozzle exit of the plasma jet. HS powder is collected at an axial distance of the nozzle about $1000 \mathrm{~mm}$ away from the nozzle exit. YSZ powder was processed under two different conditions. Under the first condition, the powder was processed without a heat preservation zone (Figure 1a). HS powder obtained under this condition was named HS1. Under the second condition, processing was conducted with a heat preservation zone around the flying path of the powder with controlled temperatures up to $2973 \mathrm{~K}$ (Figure 1b). The HS obtained under this condition was named HS2.

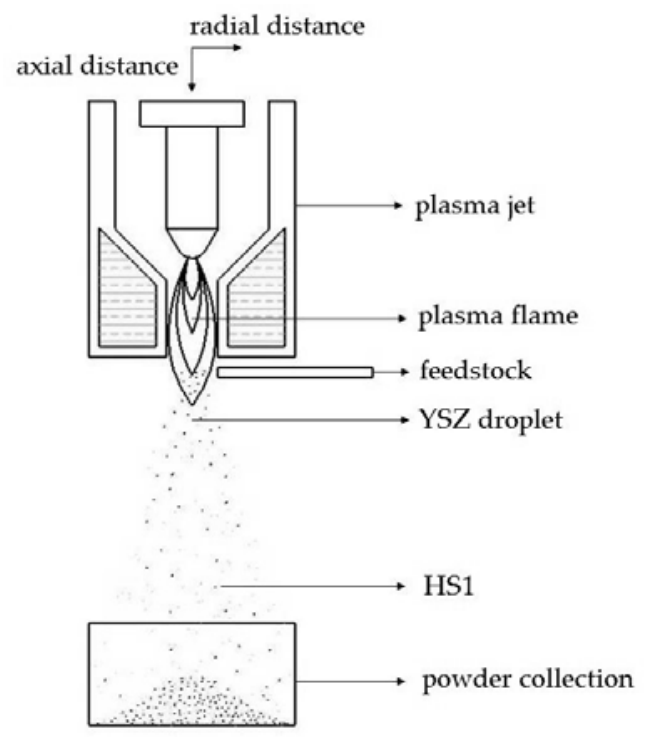

(a)

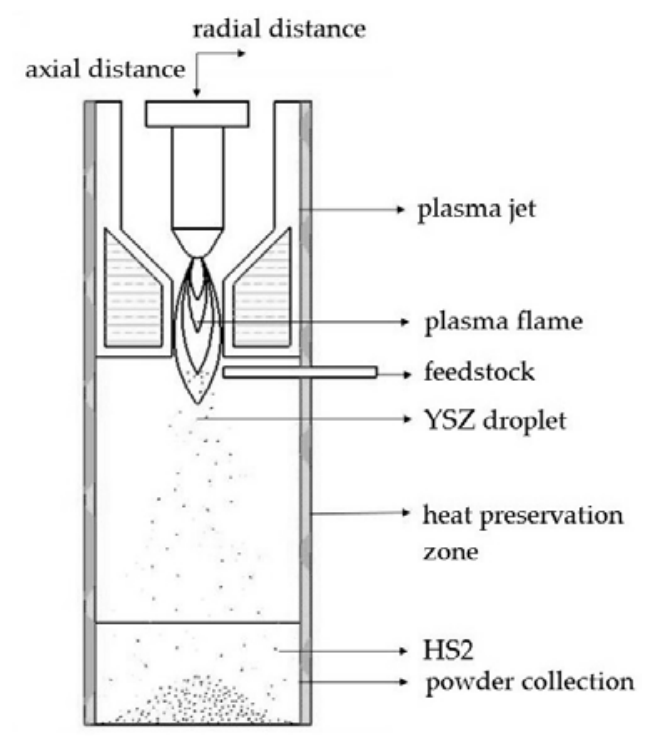

(b)

Figure 1. Preparation of HS1 and HS2 by different plasma process: (a) process without heat preservation zone; (b) process with heat preservation zone.

The apparent density of powders was measured using a Hall flow meter (Dandong Bettersize Instruments Ltd., Dandong, China). A scanning electron microscopy (SEM) JSM-6460LV (JEOL Ltd., 
Tokyo, Japan) was used to characterize the microstructures of powders. SEM images of the cross-section of the powders were used to statistically measure the shell thickness and the diameter of the powders.

\section{Results and Discussion}

Figure 2 shows the SEM images of the initial agglomerated YSZ powder and plasma processed powder. Figure 2a clearly shows the coarse surface of the agglomerated YSZ powder. However, after the plasma process, the surface of the powder became smooth and the body became more circular, indicating the melting of the powder by the plasma flame and restructuring under the surface tension of liquid (Figure 2b,c). Figure 2c exhibits the morphology of HS2 powder, revealing the existence of some particles with a broken shell, which indicates reduced shell thickness.

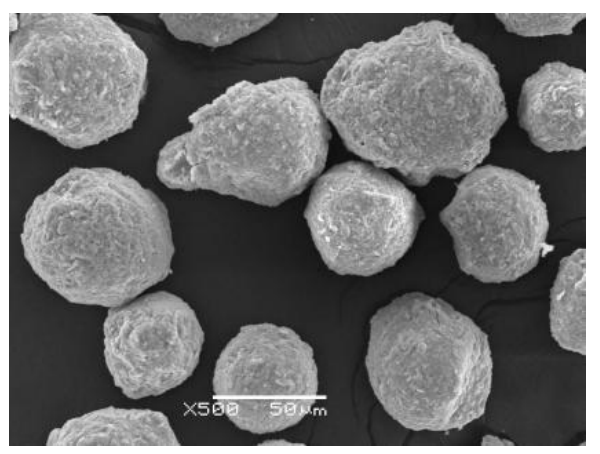

(a)

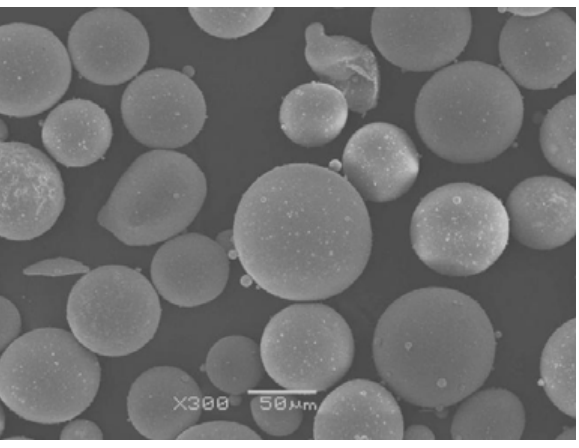

(b)

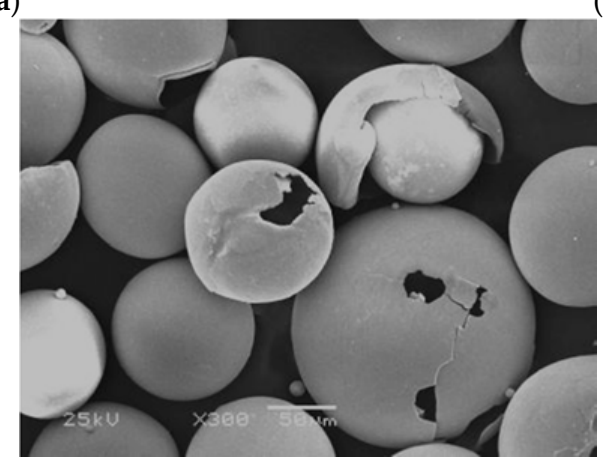

(c)

Figure 2. SEM images of yttria-stabilized zirconia (YSZ) powder. (a) YSZ agglomerated powder; (b) HS1; and (c) HS2.

Figure 3 shows the SEM images of the cross-section of the initial agglomerated YSZ powder and plasma processed powder. Figure 3a displays the solid inner structure of the initial agglomerated powder. However, the plasma-processed powder exhibited a hollow structure with a large pore in the center. The difference between the HS1 and HS2 powders was that the shell thickness of HS2 was less than that of HS1.

From Figure 4, statistically by 113 SEM images of AS, 105 SEM images of HS1, and 123 SEM images of HS2, the average relative particle diameters of AS, HS1, and HS2 were about 50.67 and $82 \mu \mathrm{m}$, the average relative shell thicknesses were about 25.8 and $3 \mu \mathrm{m}$, respectively. Through the measurements of the Hall flow meter, the apparent densities of AS, HS1, and HS2 were about 2.5, 2.3 , and $1.8 \mathrm{~g} \mathrm{~cm}^{-3}$, respectively. Clearly, powder with a reduced shell thickness could be produced conveniently by controlling the ambient temperature.

To analyze the mechanism of obtaining a reduced shell thickness of the plasma-processed HS powder under ambient temperature conditions, the temperature distribution of the plasma process without a heat preservation zone was simulated by using Jets \& Poudres software developed by Limoges University (CP/OL, University of Limoges, France). The working conditions of the plasma 
process used for the simulation were the same as those listed in Table 1. The physical properties of the YSZ agglomerated powder used for the simulation were obtained from the literature report by Ettouil et al. [66].

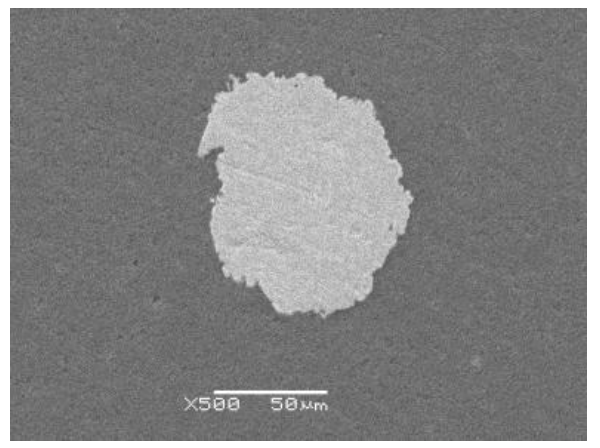

(a)

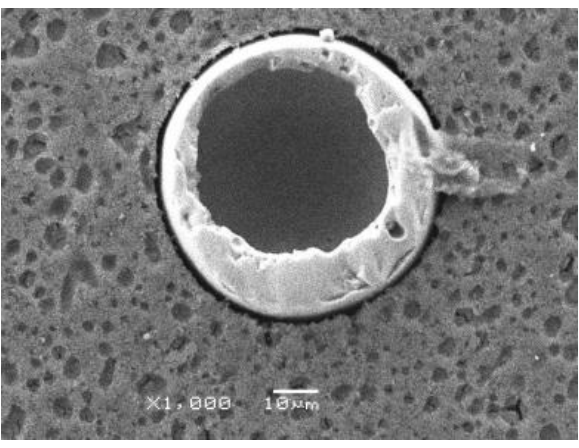

(b)

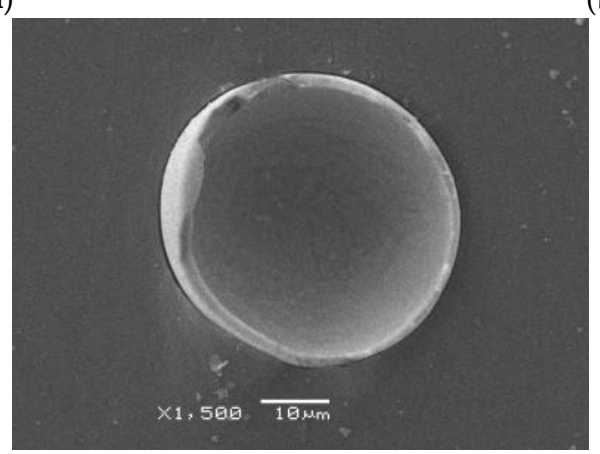

(c)

Figure 3. SEM images of the cross-section of YSZ particles. (a) YSZ agglomerated powder; (b) HS1; and (c) HS2.

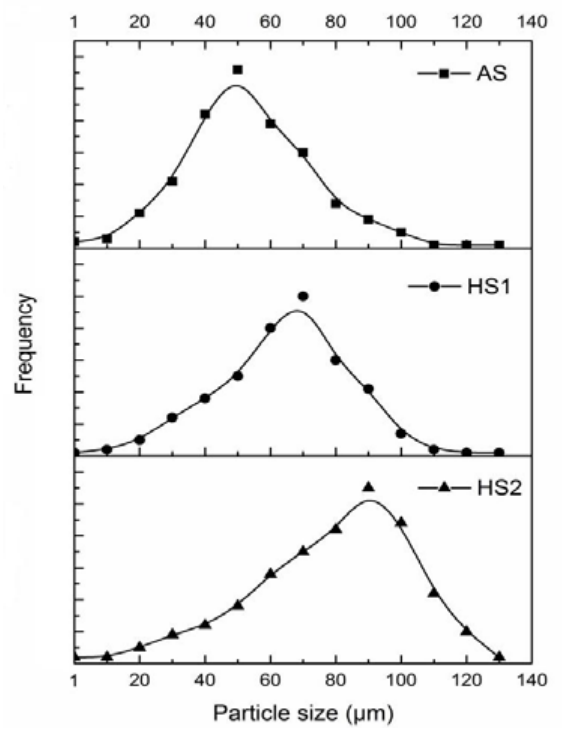

(a)

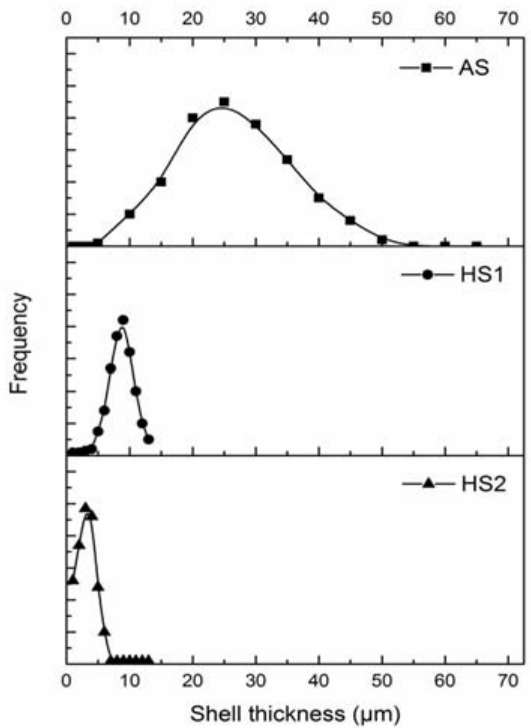

(b)

Figure 4. Particle size and shell thickness of three powders: (a) particle size of AS, HS1, and HS2; (b) shell thickness of AS, HS1, and HS2. (* Statistics by SEM images, and the shell thickness of the AS powder was taken as the radius of the powder since this powder is of an apparently dense structure with no large pore). 
Figure 5 presents the center temperature of the plasma flame with an axial distance of plasma jet and the evolution of the molten percentage of a single agglomerated YSZ particle with an axial distance of the plasma jet. The center temperature of the plasma flame at the nozzle exit was about 10,000 K and dropped rapidly with the increase of axial distance (Figure 5a). The molten percentage is defined as the molten volume to full volume of a particle. When the particle enters into the plasma plume, it melts gradually from the outside to the inside due to its low thermal conductivity. The particle began to melt at an axial distance of $40 \mathrm{~mm}$ away from the nozzle exit. The molten percentage increased with the increasing flying distance of the particle and reached $100 \%$ at an axial distance of about $80 \mathrm{~mm}$, which indicated that the particle became a liquid droplet at this location. At an axial distance far away of about $105 \mathrm{~mm}$, the molten percentage began to decrease, indicating the solidification of the droplet.

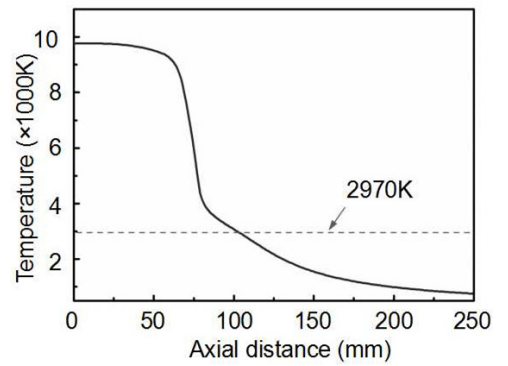

(a)

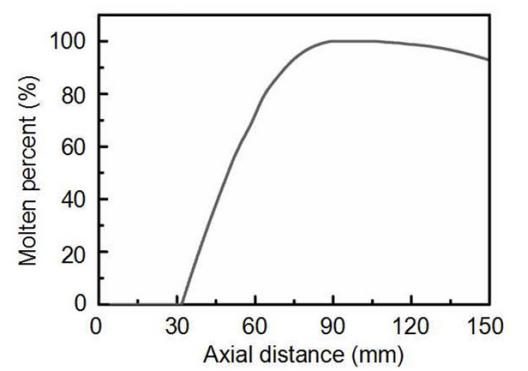

(b)

Figure 5. (a) Center temperatures of plasma flame and (b) molten percentage of YSZ agglomerated powder along axial distance in the plasma process.

Figure 6 shows the curve of the surface and center temperature of a particle with an axial distance of the plasma jet. With the increase of axial distance, the surface temperature increased rapidly above the melting index of YSZ; however, the center temperature increased slowly. The large temperature discrepancy between the surface and center of the particle can be attributed to the low thermal conductivity of YSZ. The surface temperature of the particle reached the maxima and began to drop at a distance of about $60 \mathrm{~mm}$; nonetheless, the center temperature still increased. Both the surface and the center temperature reached the melting index at a distance of about $105 \mathrm{~mm}$. At a distance greater than $105 \mathrm{~mm}$, the outer temperature was lower than the center temperature; however, the center temperature still kept increasing slowly.

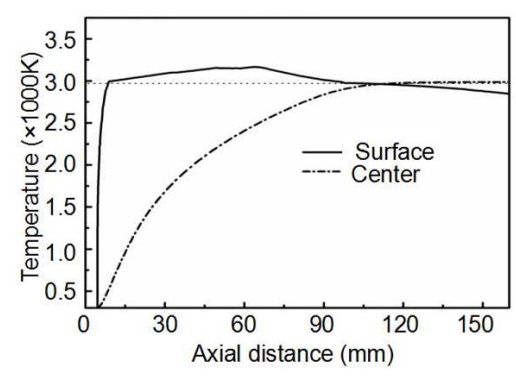

Figure 6. Surface and center temperature of a single agglomerated YSZ particle during the plasma process.

The particle in the plasma process included three main stages: (i) The AS YSZ powders injected into the plasma torch reached the melting point quickly and totally melted into droplets, which was defined as stage I; (ii) Then, the droplets' flight region was defined as stage II; and (iii) When the droplets left region II, the droplet solidified from the surface to the cavity to become HOSP particles, which was defined as stage III. The simulation is shown in Figure 7. 


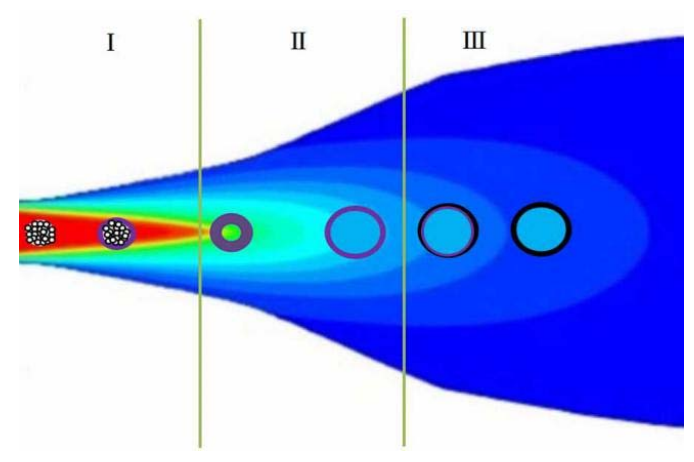

Figure 7. Evolution of a particle in the plasma flame.

According to Solonenko [63], when the particle melts completely in stage II, the formed droplet acquires a force balance between inner pressure $P_{g}$, surface tension $P_{\sigma}$, and ambient pressure $P_{a}$. The gas volume inside the droplets should not excessively increase, and the load on the droplet should be kept balanced

$$
P_{g}=P_{a}+P_{\sigma}
$$

Thus, the higher the inner temperature, the higher the $P_{g}$; and the droplet expands under $P_{g}$ with a larger volume and reduced shell thickness. Nonetheless, when the outer temperature of the droplet is lower than melting index of YSZ, it begins to solidify gradually from the surface to the center as shown in stage III; at this time, the droplet cannot expand any further. However, as shown in Figure 1b, if the ambient temperature is preserved above the melting index-which means stage II expansion-the outer surface of the droplet does not solidify, and the droplet can still expand with the increase in inner temperature, thus the particle with a larger volume and reduced thickness can be obtained after the solidification of the droplet.

\section{Conclusions}

YSZ HS powder with a reduced shell thickness was prepared by providing a heat preservation zone around the flying path of the particle during the plasma process. YSZ HS powder exhibited a shell thickness of about $3 \mu \mathrm{m}$ when compared to the HS powder prepared by the plasma process without a heat preservation zone, which exhibited a shell thickness of about $8 \mu \mathrm{m}$. The mechanism of the formation of HS powder with a reduced shell thickness was that the droplet melted from the YSZ particle could expand more sufficiently in the heat preservation zone, which could prevent the solidification of the outer surface of droplets during the plasma process.

The results obtained from this article can be summarized as follows:

- HS2 has a larger particle diameter, thinner shell thickness, and lower apparent density than that of AS and HS1.

- For the main conditions of preparation of HS2 by the plasma process, aside from the amount of gas entrapped, entrapped gas pressure and ambient pressure, ambient temperature should also be taken into consideration, which prevents the surface from premature solidification.

- By adding a heat preservation zone around the particle flying path during the plasma process, HS could be obtained with a larger particle diameter and thinner shell thickness.

Author Contributions: Conceptualization, L.Z. and Z.Z.; Methodology, L.Z.; Validation, Z.Z. and Y.G.; Investigation, Y.G.; Resources, H.C.; Data Curation, Y.D.; Writing-Original Draft Preparation, L.Z.; Writing-Review \& Editing, Y.D.

Funding: This research was funded by National Science Foundation of China (No. 21676163).

Acknowledgments: The authors would like to thank Zheng Wang, Yi Yang, Bo Gao, Miao Bai, Songgeng Ge for excellent technical and material support. 
Conflicts of Interest: The authors declare no conflict of interest.

\section{References}

1. Bakan, E.; Vaßen, R. Ceramic top coats of plasma-sprayed thermal barrier coatings: Materials, processes, and properties. J. Therm. Spray Technol. 2017, 26, 992-1010. [CrossRef]

2. Igumenov, I.K.; Aksenov, A.N. Thermal barrier coatings on gas turbine blades: Chemical vapor deposition (Review). Therm. Eng. 2017, 64, 865-873. [CrossRef]

3. Mishra, R.K. Life enhancement of gas turbine combustor liner through thermal barrier coating. J. Fail. Anal. Prev. 2017, 17, 914-918. [CrossRef]

4. Donegan, S.P.; Rollett, A.D. Simulation of residual stress and elastic energy density in thermal barrier coatings using fast Fourier transforms. Acta Mater. 2015, 96, 212-228. [CrossRef]

5. Mauer, G.; Du, L.; Vaßen, R. Atmospheric plasma spraying of single phase lanthanum zirconate thermal barrier coatings with optimized porosity. Coatings 2016, 6, 49. [CrossRef]

6. Chen, X.G.; Zhang, H.; Zhang, H.S.; Zhao, Y.D.; Gang, L.I. $\mathrm{Ce}_{1-x} \mathrm{Sm}_{\mathrm{x}} \mathrm{O}_{2-x / 2}-\mathrm{A}$ novel type of ceramic material for thermal barrier coatings. J. Adv. Ceram. 2016, 5, 244-252. [CrossRef]

7. Wang, X.F.; Xiang, H.M.; Feng, J.C.; Zhou, Y.C. Mechanical properties and damage tolerance of bulk $\mathrm{Yb}_{3} \mathrm{Al}_{5} \mathrm{O}_{12}$ ceramic. J. Mater. Sci. Technol. 2015, 31, 369-374. [CrossRef]

8. Tang, W.Z.; Yang, L.; Zhu, W.; Zhou, Y.C.; Guo, J.W.; Lu, C. Numerical simulation of temperature distribution and thermalstress field in a turbine blade with multilayer-structure TBCs by a fluid-solid coupling method. J. Mater. Sci. Technol. 2016, 32, 452-458. [CrossRef]

9. Huang, J.; Wang, W.; Lu, X.; Hu, D.; Feng, Z.; Guo, T. Effect of particle size on the thermal shock resistance of plasma-sprayed YSZ coatings. Coatings 2017, 7, 150. [CrossRef]

10. Guo, L.; Li, M.Z.; Zhang, Y. Improved toughness and thermal expansion of non-stoichiometry $\mathrm{Gd}_{2-x} \mathrm{Zr}_{2+x} \mathrm{O}_{7+\mathrm{X} / 2}$ ceramics for thermal barrier coating application. J. Mater. Sci. Technol. 2016, 32, $28-33$. [CrossRef]

11. Kang, Y.X.; Bai, Y.; Yuan, T.; Wang, Y.; Fan, W.; Gao, Y.; Bao, C.G.; Chen, H.Y.; Li, B.Q. Thermal cycling lives of plasma sprayed YSZ based thermal barrier coatings in a burner rig corrosion test. Surf. Coat. Technol. 2017, 324, 307-317. [CrossRef]

12. Ghasemi, R.; Vakilifard, H. Plasma-sprayed nanostructured YSZ thermal barrier coatings: Thermal insulation capability and adhesion strength. Ceram. Int. 2017, 12, 8556-8563. [CrossRef]

13. Zhou, D.; Guillon, O.; Vaßen, R. Development of YSZ thermal barrier coatings using axial suspension plasma spraying. Coatings 2017, 7, 120. [CrossRef]

14. Huang, J.; Wang, W.; Yu, J.; Wu, L.; Feng, Z. Effect of particle size on the micro-cracking of plasma-sprayed YSZ coatings during thermal cycle testing. J. Therm. Spray Technol. 2017, 26, 755-763. [CrossRef]

15. Cheng, B.; Yang, N.; Zhang, Q.; Zhang, M.; Zhang, Y.M.; Chen, L.; Yang, G.J.; Li, C.X.; Li, C.J. Sintering induced the failure behavior of dense vertically crack and lamellar structured TBCs with equivalent thermal insulation performance. Ceram. Int. 2017, 47, 15459-15465. [CrossRef]

16. Yang, G.J.; Chen, Z.L.; Li, C.X.; Li, C.J. Microstructural and mechanical property evolutions of plasma-sprayed YSZ coating during high-temperature exposure: Comparison study between 8YSZ and 20YSZ. J. Therm. Spray Technol. 2013, 22, 1294-1302. [CrossRef]

17. Cheng, B.; Zhang, Y.M.; Yang, N.; Zhang, M.; Chen, L.; Yang, G.J.; Li, C.X.; Li, C.J. Sintering-induced delamination of thermal barrier coatings by gradient thermal cyclic test. J. Am. Ceram. Soc. 2017, 100, 1820-1830. [CrossRef]

18. Li, G.R.; Li, C.X.; Li, C.J.; Yang, G.J. Sintering characteristics of plasma-sprayed TBCs: Experimental analysis and an overall modelling. Ceram. Int. 2018, 44, 2982-2990. [CrossRef]

19. Li, G.R.; Yang, G.J.; Li, C.X.; Li, C.J. Force transmission and its effect on structural changes in plasma-sprayed lamellar ceramic coatings. J. Eur. Ceram. Soc. 2017, 37, 2877-2888. [CrossRef]

20. Johnson, S.L.; Venugopal, G.; Hunt, A.T. Flame-assisted flash sintering: A noncontact method to flash sinter coatings on conductive substrates. J. Am. Ceram. Soc. 2018, 101, 536-541. [CrossRef]

21. Li, G.; Xie, H.; Yang, G.; Liu, G.; Li, C.; Li, C. A comprehensive sintering mechanism for TBCs-Part I: An overall evolution with two-stage kinetics. J. Am. Ceram. Soc. 2017, 100, 2176-2189. [CrossRef] 
22. Li, G.; Xie, H.; Yang, G.; Liu, G.; Li, C.; Li, C. A comprehensive sintering mechanism for TBCs-Part II: Multiscale multipoint interconnection-enhanced initial kinetics. J. Am. Ceram. Soc. 2017, 100, 4240-4251. [CrossRef]

23. Shinozaki, M.; Clyne, T.W. A methodology, based on sintering-induced stiffening, for prediction of the spallation lifetime of plasma-sprayed coatings. Acta Mater. 2013, 61, 579-588. [CrossRef]

24. Li, G.; Yang, G.; Li, C.; Li, C. A comprehensive sintering mechanism for thermal barrier coatings-Part III: Substrate constraint effect on healing of 2D pores. J. Am. Ceram. Soc. 2018, 101, 3636-3648. [CrossRef]

25. Cocks, A.C.F.; Fleck, N.A. Constrained sintering of an air-plasma-sprayed thermal barrier coating. Acta Mater. 2010, 58, 4233-4244. [CrossRef]

26. Li, G.R.; Yang, G.J.; Li, C.X.; Li, C.J. Strain-induced multiscale structural changes in lamellar thermal barrier coatings. Ceram. Int. 2016, 43, 2252-2266. [CrossRef]

27. Li, G.R.; Cheng, B.; Yang, G.J.; Li, C.X. Strain-induced stiffness-dependent structural changes and the associated failure mechanism in TBCs. J. Eur. Ceram. Soc. 2017, 37, 3609-3621. [CrossRef]

28. Cheng, B.; Yang, G.J.; Zhang, Q.; Yang, N.; Zhang, M.; Zhang, Y.; Li, C.X.; Li, C.J. Gradient thermal cyclic behaviour of $\mathrm{La}_{2} \mathrm{Zr}_{2} \mathrm{O}_{7} /$ YSZ DCL-TBCs with equivalent thermal insulation performance. J. Eur. Ceram. Soc. 2017, 38, 1888-1896. [CrossRef]

29. Wang, W.; Wei, J.; Hong, H.; Xuan, F.; Shan, Y. Effect of processing and service conditions on the luminescence intensity of plasma sprayed $\left(\mathrm{Tm}^{+}+\mathrm{Dy}^{+}\right)$co-doped YSZ coatings. J. Alloys Compd. 2014, 584, $136-141$. [CrossRef]

30. Chen, X.; Zhang, H.; Sun, K.; Dang, X.; Zhang, H.; Ren, B.; Tang, A. Thermal conductivity and expansion coefficient of $\left(\mathrm{Sm}_{1-\mathrm{x}} \mathrm{Yb}_{\mathrm{x}}\right)_{2} \mathrm{Ce}_{2} \mathrm{O}_{7}$ ceramics for thermal barrier coatings. J. Mater. Eng. Perform. 2017, 26, 6193-6197.

31. Li, G.R.; Lei, J.; Yang, G.J.; Li, C.X.; Li, C.J. Substrate-constrained effect on the stiffening behavior of lamellar thermal barrier coatings. J. Eur. Ceram. Soc. 2018, 38, 2579-2587. [CrossRef]

32. Liu, M.J.; Zhang, M.; Zhang, Q.; Yang, G.J.; Li, C.X.; Li, C.J. The gaseous material capacity of open plasma jet in plasma spray-physical vapor deposition process. Appl. Surf. Sci. 2017, 428, 877-884. [CrossRef]

33. Schmitt, M.P.; Harder, B.J.; Wolfe, D.E. Process-structure-property relations for the erosion durability of plasma spray-physical vapor deposition (PS-PVD) thermal barrier coatings. Surf. Coat. Technol. 2016, 297, 11-18. [CrossRef]

34. Chen, Q.Y.; Peng, X.Z.; Yang, G.J.; Li, C.X.; Li, C.J. Characterization of plasma jet in plasma spray-physical vapor deposition of YSZ using a $<80 \mathrm{~kW}$ shrouded torch based on optical emission spectroscopy. J. Therm. Spray Technol. 2015, 24, 1038-1045.

35. Li, M.; Guo, L.; Ye, F. Phase structure and thermal conductivities of $\mathrm{Er}_{2} \mathrm{O}_{3}$ stabilized $\mathrm{ZrO}_{2}$ toughened $\mathrm{Gd}_{2} \mathrm{Zr}_{2} \mathrm{O}_{7}$ ceramics for thermal barrier coatings. Ceram. Int. 2016, 42, 16584-16588. [CrossRef]

36. Liu, M.J.; Zhang, M.; Zhang, Q.; Yang, G.J.; Li, C.X.; Li, C.J. Evaporation of Droplets in Plasma Spray-Physical Vapor Deposition Based on Energy Compensation Between Self-Cooling and Plasma Heat Transfer. J. Therm. Spray Technol. 2017, 26, 1641-1650. [CrossRef]

37. Keshavarz, M.; Idris, M.H.; Ahmad, N. Mechanical properties of stabilized zirconia nanocrystalline EB-PVD coating evaluated by micro and nano indentation. J. Adv. Ceram. 2013, 2, 333-340. [CrossRef]

38. Tian, L.; Feng, Z.; Xiong, W. Microstructure, microhardness, and wear resistance of AlCoCrFeNiTi/Ni60 coating by plasma spraying. Coatings 2018, 8, 112. [CrossRef]

39. Xie, H.; Xie, Y.C.; Yang, G.J.; Li, C.X.; Li, C.J. Modeling thermal conductivity of thermally sprayed coatings with intrasplat cracks. J. Therm. Spray Technol. 2013, 22, 1328-1336. [CrossRef]

40. Li, G.R.; Lv, B.W.; Yang, G.J.; Zhang, W.X.; Li, C.X.; Li, C.J. Relationship between lamellar structure and elastic modulus of thermally sprayed thermal barrier coatings with intra-splat cracks. J. Therm. Spray Technol. 2015, 24, 1355-1367. [CrossRef]

41. Yang, G.J.; Li, C.J.; Li, C.X.; Kondoh, K.; Ohmori, A. Improvement of adhesion and cohesion in plasma-sprayed ceramic coatings by heterogeneous modification of nonbonded lamellar interface using high strength adhesive infiltration. J. Therm. Spray Technol. 2013, 22, 36-47. [CrossRef]

42. Yang, G.J.; Li, C.X.; Li, C.J. Characterization of nonmelted particles and molten splats in plasma-sprayed $\mathrm{Al}_{2} \mathrm{O}_{3}$ coatings by a combination of scanning electron microscopy, $X$-ray diffraction analysis, and confocal raman analysis. J. Therm. Spray Technol. 2013, 22, 131-137. [CrossRef] 
43. Zhang, W.W.; Li, G.R.; Zhang, Q.; Yang, G.J. Comprehensive damage evaluation of localized spallation of thermal barrier coatings. J. Adv. Ceram. 2017, 6, 230-239. [CrossRef]

44. Zhang, W.W.; Li, G.R.; Zhang, Q.; Yang, G.J. Multiscale pores in TBCs for lower thermal conductivity. Chem. Phys. Lett. 2012, 546, 1183-1197. [CrossRef]

45. Gao, P.H.; Yang, G.J.; Cao, S.T.; Li, J.P.; Yang, Z.; Guo, Y.C. Heredity and variation of hollow structure from powders to coatings through atmospheric plasma spraying. Surf. Coat. Technol. 2016, 305, 76-82. [CrossRef]

46. Li, G.R.; Yang, G.J.; Li, C.X.; Li, C.J. Stage-sensitive microstructural evolution of nanostructured TBCs during thermal exposure. J. Eur. Ceram. Soc. 2018, 38, 3325-3332. [CrossRef]

47. Li, G.R.; Yang, G.J.; Li, C.X.; Li, C.J. A comprehensive mechanism for the sintering of plasma-sprayed nanostructured thermal barrier coatings. Ceram. Int. 2017, 43, 9600-9615. [CrossRef]

48. Chen, L.; Yang, G.J.; Li, C.X.; Li, C.J. Hierarchical formation of intrasplat cracks in thermal spray ceramic coatings. J. Therm. Spray Technol. 2016, 25, 959-970. [CrossRef]

49. Chen, L.; Yang, G.J.; Li, C.X.; Li, C.J. Edge effect on crack patterns in thermally sprayed ceramic splats. J. Therm. Spray Technol. 2016, 26, 302-314. [CrossRef]

50. Yang, G.J.; Li, C.X.; Hao, S.; Xing, Y.Z.; Yang, E.J.; Li, C.J. Critical bonding temperature for the splat bonding formation during plasma spraying of ceramic materials. Surf. Coat. Technol. 2013, 235, 841-847. [CrossRef]

51. Chen, L.; Yang, G.J.; Li, C.X. Formation of lamellar pores for splats via interfacial or sub-interfacial delamination at chemically bonded region. J. Therm. Spray Technol. 2017, 26, 315-326. [CrossRef]

52. Kulkarni, A.; Herman, H. Microstructure-property correlations in industrial thermal barrier coatings. J. Am. Ceram. Soc. 2010, 87, 1294-1300. [CrossRef]

53. Chen, L.; Yang, G.J. Anomalous epitaxial growth in thermally sprayed YSZ and LZ splats. J. Therm. Spray Technol. 2017, 26, 1168-1182. [CrossRef]

54. Chen, L.; Yang, G.J. Epitaxial growth and cracking of highly tough 7YSZ splats by thermal spray technology. J. Adv. Ceram. 2018, 7, 17-29. [CrossRef]

55. Bakan, E.; Mack, D.E.; Mauer, G.; Mücke, R.; Vaßen, R. Porosity-property relationships of plasma-sprayed $\mathrm{Gd}_{2} \mathrm{Zr}_{2} \mathrm{O}_{7} / \mathrm{YSZ}$ thermal barrier coatings. J. Am. Ceram. Soc. 2015, 98, 2647-2654. [CrossRef]

56. Li, C.J.; Ohmori, A. Relationships between the microstructure and properties of thermally sprayed deposits. J. Therm. Spray Technol. 2003, 12, 365-374. [CrossRef]

57. Chen, L.; Yang, G.J. Epitaxial growth and cracking mechanisms of thermally sprayed ceramic splats. J. Therm. Spray Technol. 2018, 27, 255-268. [CrossRef]

58. Chen, L.; Gao, L.L.; Yang, G.J. Imaging slit pores under delaminated splats by white light interference. J. Therm. Spray Technol. 2018, 27, 319-335. [CrossRef]

59. Herman, H. Powders for thermal spray technology. KONA 1991, 9, 187-199. [CrossRef]

60. Li, F.; Li, Y.; Xu, K.; Song, Z.; Zhang, Z.; Cui, H.; Li, Z. Research progress of the preparation of zirconia hollow sphere powder and the performance of its coating. Rare Met. Mater. Eng. 2014, 43, 3183-3187.

61. Tan, Y.; Srinivasan, V.; Nakamura, T.; Sampath, S.; Bertrand, P.; Bertrand, G. Optimizing compliance and thermal conductivity of plasma sprayed thermal barrier coatings via controlled powders and processing strategies. J. Therm. Spray Technol. 2012, 21, 950-962. [CrossRef]

62. Gulyaev, I.P.; Solonenko, O.P. Hollow droplets impacting onto a solid surface. Exp. Fluids 2013, 54, 1432-1443. [CrossRef]

63. Solonenko, O.P.; Gulyaev, I.P.; Smirnov, A.V. Plasma processing and deposition of powdered metal oxides consisting of hollow spherical particles. Tech. Phys. Lett. 2008, 34, 1050-1052. [CrossRef]

64. Solonenko, O.P.; Gulyaev, I.P.; Smirnov, A.V. Thermal plasma processes for production of hollow spherical powders. J. Stat. Mech. 2011, 6, 219-234.

65. Gulyaev, I.P. Production and modification of hollow powders in plasma under controlled pressure. J. Phys. 2013, 1, 303-311. [CrossRef]

66. Ettouil, F.B.; Mazhorova, O.; Pateyron, B.; Ageorges, H.; El Ganaoui, M.; Fauchais, P. Predicting dynamic and thermal histories of agglomerated particles injected within a d.c. plasma jet. Surf. Coat. Technol. 2008, 202, 4491-4495. [CrossRef]

(C) 2018 by the authors. Licensee MDPI, Basel, Switzerland. This article is an open access article distributed under the terms and conditions of the Creative Commons Attribution (CC BY) license (http://creativecommons.org/licenses/by/4.0/). 